\title{
Fatal toxicity of antidepressant drugs in overdose
}

\author{
SIMON CASSIDY, JOHN HENRY
}

\begin{abstract}
A fatal toxicity index (deaths per million National Health Service prescriptions) was calculated for antidepressant drugs on sale during the years 1975-84 in England, Wales, and Scotland. The tricyclic drugs introduced before 1970 had a higher index than the mean for all the drugs studied $(p<0.001)$. In this group the toxicity of amitriptyline, dibenzepin, desipramine, and dothiepin was significantly higher, while that of clomipramine, imipramine, iprindole, protriptyline, and trimipramine was lower. The monoamine oxidase inhibitors had intermediate toxicity, and the antidepressants introduced since 1973, considered as a group, had significantly lower toxicity than the mean $(p<0.001)$. Of these newer drugs, maprotiline had a fatal toxicity index similar to that of the older tricyclic antidepressants, while the other newly introduced drugs had lower toxicity indices, with those for mianserin, nomifensine, trazodone, and viloxazine reaching significance. Provided that these drugs are equally effective clinically, serious consideration should be given to prescribing antidepressants with a lower fatal toxicity.
\end{abstract}

\section{Introduction}

The frequency with which a drug causes fatal poisoning depends on its intrinsic toxicity and its availability. ${ }^{2}$ It is impossible to estimate the numbers of people treated with each drug, but Britain is one of the few countries where availability may be estimated from records, collated by the National Health Service, of the number of prescriptions issued. Several authors have calculated a fatal toxicity index, expressed as the number of deaths per million prescriptions, to compare the relative dangers of different drugs. ${ }^{3-6}$ Differences in the indices, particularly among the members of a single class of drug, may indicate the presence or absence of features that predispose to a fatal outcome when a drug is taken in overdose. The index may therefore be used to identify drugs that may be particularly

National Poisons Unit, Guy's Hospital, London SE1 9RT

SIMON CASSIDY, MSC, research fellow

JOHN HENRY, FRCP, consultant physician

Correspondence to: Dr J Henry, Poisons Unit, New Cross Hospital, London SE14 5ER. dangerous in overdose, thus meriting investigation of their toxic properties and closer consideration of the circumstances in which they are prescribed. Recommendations may thus be made that might reduce the number of fatalities.

We used national mortality statistics and prescription data to compile fatal toxicity indices for the currently available antidepressant drugs to assess the comparative safety of the different antidepressant drugs from an epidemiological standpoint. Owing to the nature of the disease these drugs are particularly likely to be taken in overdose and often cause death.

\section{Sources of information and methods}

The statistical sources used list drugs under their generic and proprietary names. The antidepressants available during the 10 years $1975-84$, and all the proprietary names under which they were sold, were identified from the British National Formulary, the Association of the British Pharmaceutical Industry's Data Sheet Compendium, and the Department of Health and Social Security's prescription analysis drug master index. ${ }^{78}$ These included the following drugs, which were introduced after 1975: mianserin (1976), nomifensine (1977), trazodone (1980), and lofepramine (1983).

\section{MORTALITY STATISTICS}

The numbers of deaths due to acute poisoning were obtained from tables 9 and 10 of the Office of Population Censuses and Surveys' publication Mortality statistics-accidents and violence (England and Wales) for 1975-84 and supplemented with unpublished data for 1981 and $1984 .^{9}$ Figures for deaths due to acute poisoning with antidepressants in Scotland were extracted from the Registrar General's annual reports for 1975-84, supplied by the General Register Office for Scotland. ${ }^{10}$ Deaths due to adverse reactions, chronic exposure, addiction to a chemical, or chemically induced psychoses were not included in the figures. Only deaths recorded as having been caused by one drug, or one drug plus alcohol (which occurred in only a few cases), were included.

\section{PRESCRIPTION DATA}

The statistics and research division of the Department of Health and Social Security supplied prescription data for England, Scotland, and Wales for the years 1975-84 (list D for 1975-9 and list B for 1980-4), as provided by a 1 in 200 sample of data - that is, a sample of 1 in 20 prescriptions dispensed by 1 in 10 retail pharmacists for general medical practices within the National Health Service. Private general practice and most hospitals were 
TABLE I-Numbers of deaths, prescription data, and fatal toxicity indices for all antidepressants 1975-84 in England, Wales, and Scotland

\begin{tabular}{|c|c|c|c|c|c|c|c|c|}
\hline & \multirow{2}{*}{\multicolumn{2}{|c|}{ Fatal poisonings }} & \multirow{3}{*}{$\begin{array}{l}\text { No of } \\
\text { prescriptions } \\
\text { (millions) }\end{array}$} & \multirow{3}{*}{$\begin{array}{l}\text { No of standard } \\
\text { quantity units } \\
\text { prescribed } \\
\text { (millions) }\end{array}$} & \multirow{3}{*}{$\begin{array}{l}\text { Weight } \\
\text { prescribed } \\
\left(\times 10^{3} \mathrm{~kg}\right)\end{array}$} & \multicolumn{3}{|c|}{ Fatal toxicity indices } \\
\hline & & & & & & \multirow{2}{*}{$\begin{array}{l}\text { No of deaths } \\
\text { per million } \\
\text { prescriptions } \\
\text { (95\% confidence } \\
\text { intervals) }\end{array}$} & \multirow{2}{*}{$\begin{array}{c}\text { No of deaths } \\
\text { per } 10^{9} \\
\text { standard } \\
\text { quantity units }\end{array}$} & \multirow{2}{*}{$\begin{array}{c}\text { No of deaths } \\
\text { per } 10^{3} \mathrm{~kg}\end{array}$} \\
\hline . & No observed & No expected & & & & & & \\
\hline $\begin{array}{l}\text { Tricyclic antidepressants } 1970 \text { and before } \\
\text { Monoamine oxidase inhibitors } \\
\text { Tricyclic and other antidepressants } 1974 \text { and after }\end{array}$ & $\begin{array}{r}2384 \\
42 \\
125\end{array}$ & $\begin{array}{r}2160 \cdot 1 \\
54 \cdot 8 \\
336 \cdot 8\end{array}$ & $\begin{array}{l}61 \cdot 9 \\
1.57 \\
9.65\end{array}$ & $\begin{array}{r}4695 \\
132 \\
550\end{array}$ & $\begin{array}{r}115 \cdot 4 \\
1.8 \\
16 \cdot 4\end{array}$ & $\begin{array}{l}38 \cdot 5^{\star \star \star \star}(36 \cdot 9 \text { to } 40 \cdot 1) \\
26 \cdot 7 \quad(18 \cdot 6 \text { to } 34 \cdot 8) \\
13 \cdot 0^{\star \star \star}(10 \cdot 7 \text { to } 15 \cdot 3)\end{array}$ & $\begin{array}{l}508 \\
319 \\
227\end{array}$ & $\begin{array}{r}20 \cdot 6 \\
23 \cdot 1 \\
7 \cdot 6\end{array}$ \\
\hline All antidepressants & 2551 & & $73 \cdot 1$ & 5376 & $133 \cdot 6$ & (33.5 to 36.3$)$ & 474 & $19 \cdot 1$ \\
\hline
\end{tabular}

$\star \star \star$ Significantly different at $0 \cdot 1 \%$ level from all antidepressants $(p<0 \cdot 001)$.

TABLE II-Fatal poisoning, prescription data, and fatal toxicity indices 1975-84 for antidepressant drugs in England, Wales, and Scotland

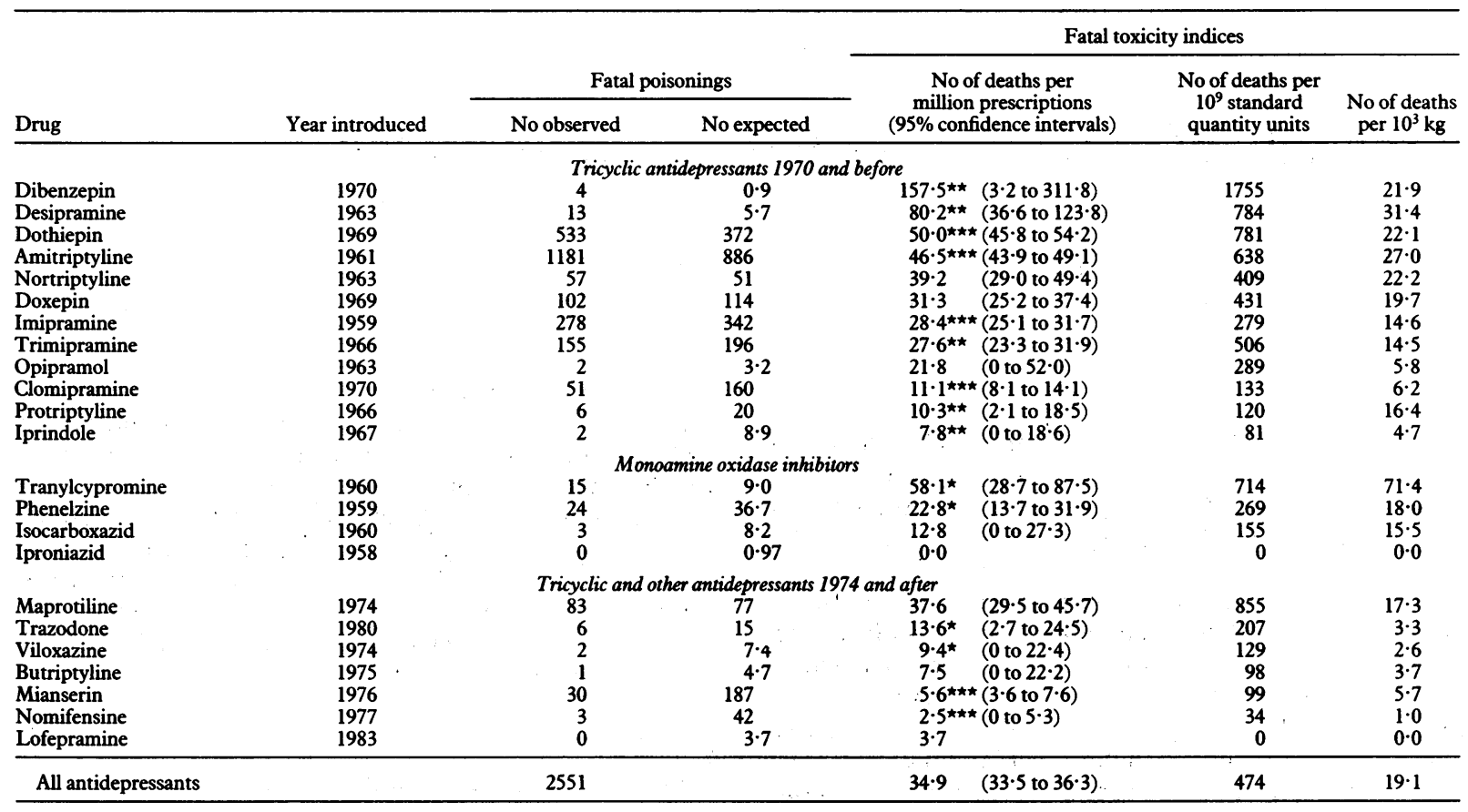

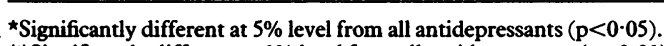

$\star \star$ Significantly different at $1 \%$ level from all antidepressants $(p<0 \cdot 01)$

$\star \star \star$ Significantly different at $0 \cdot 1 \%$ level from all antidepressants $(p<0 \cdot 001)$.

excluded. From these data, listed by generic and proprietary names, information was obtained about numbers of prescriptions and standard quantity units prescribed (including capsules, tablets, millilitres of syrup or suspension, and ampoules). The quantity ( $\mathrm{kg}$ ) of drug prescribed was then calculated.

\section{ANALYTICAL METHODS}

The drugs were assigned to three classes: monoamine oxidase inhibitors, early tricyclic antidepressants on sale before 1970, and all antidepressants on sale after 1973. Three fatal toxicity indices were calculated for each drug, for each of the three groups of antidepressants, and for all of the drugs taken together by dividing the total deaths over 10 years by the numbers of prescriptions (in millions), the number of standard quantity units prescribed $\left(\times 10^{9}\right)$, and the weight of drug prescribed $(\times 1000 \mathrm{~kg})$ for the same period or for the corresponding number of years for drugs introduced after 1975. Confidence intervals were calculated (assuming a binomial distribution) for each index based on numbers of prescriptions with the following equations:

$$
\begin{gathered}
\mathrm{CL}_{95}=1.96 \times \mathrm{SEM} \\
\mathrm{SEM}=\sqrt{\frac{\mathrm{p} \times \mathrm{q}}{\mathrm{n}}}
\end{gathered}
$$

where $\mathrm{CL}_{\mathrm{x}}=\mathrm{x} \%$ confidence interval, $\mathrm{p}=$ fatal toxicity index $/ 10^{6}, \mathrm{q}=1-\mathrm{p}$, $\mathrm{n}=$ number of prescriptions.
The number of deaths expected for each drug if it had the overall toxicity rate of $34 \cdot 9 / 10^{6}$ prescriptions was calculated, and this was compared with the observed number using a $\chi^{2}$ test for differences. Differences between the six new antidepressants (see table II) were also tested using a $\chi^{2}$ test.

\section{Results}

Table I shows the mortality figures, prescription data, and fatal toxicity $\widetilde{N}$ indices for each of the three groups. We have also included the numbers of units and the gross quantity of drug prescribed, but as there was little difference between the relative rankings of the different drugs we have not shown confidence limits or statistical values and have confined further discussion to the index of deaths per million prescriptions. The early tricyclic antidepressants as a group had a significantly higher ratio of deaths per million prescriptions than the mean for all antidepressants, while the monoamine oxidase inhibitors when grouped were not significantly different. The drugs introduced after $1973 \mathrm{had}$ a significantly lower ratio of deaths per million prescriptions than the overall mean. Table II lists the drugs in each group with their fatal toxicity indices and shows that while three of the early tricyclic agents (desipramine, dothiepin, and amitriptyline) had a higher index than the mean, five (clomipramine, imipramine, iprindole, protriptyline, and trimipramine) had a significantly lower index than the mean for all of the antidepressants. This suggests that these drugs may be safer. No deaths were recorded for iproniazid or lofepramine. Nomifensine, although withdrawn from use in 1986, was retained in the list for reference. Zimeldine, introduced in 1982 and withdrawn in 1983, was not included as it was on sale for too short a time for accurate figures to be calculated. 


\section{Discussion}

The antidepressant drugs are among those most frequently implicated in deliberate, fatal self poisoning, and members of the tricyclic group of drugs are widely believed to be among the most toxic. Most workers limit themselves to broad generalisations; Blackwell, for example, divided the antidepressant drugs into three groups: the monoamine oxidase inhibitors, the early tricyclic antidepressants, and the second generation antidepressants, which is the broad classification that we used. ${ }^{11} \mathrm{He}$ considered the second generation drugs to be safer than the two other groups. It is clearly not easy to establish a reliable indicator of the relative toxicities of the various antidepressants, although some form of comparison is necessary. The "natural experiment" of cases of self poisoning has to be taken as the starting point as the results of experiments in animals cannot reliably be extrapolated to man and the induction of even mild toxicity in man, besides being unethical, may in any case not correspond to the drug's lethal toxicity.

We believe that the fatal toxicity index is a useful means of estimating the relative danger or safety of antidepressants, in the absence of any more reliable indicator. The main criticism of the index is that it may be biased by systematic error in the mortality data or prescription data, or both. Certification of death due to poisoning is subject to inaccuracies, ${ }^{12}$ and it is impossible to confirm the causes of all such deaths by analytical techniques as some drugs, such as monoamine oxidase inhibitors, are not detectable by postmortem analysis and other antidepressants are not all detectable by a single screening method. The use of a fatal toxicity index also assumes that the number of prescriptions issued is a reliable indicator of the availability of the drug in the community. In fact, the prescription data are derived from National Health Service prescriptions issued by general practitioners, who may see a selected population of depressed patients and whose prescribing habits may differ from those of their colleagues in hospital. The choice of drug and the quantity prescribed to patients with suicidal tendencies may be made on the assumption that certain drugs are safer if taken in overdose. In addition, some antidepressants are often prescribed for conditions other than depression, such as nocturnal enuresis. No allowance has been made for such possible differences in prescribing habits. These results have provided lower fatal toxicity indices for several tricyclic antidepressants than those calculated by King and Moffat from data for 1976-8..$^{5}$ In their mortality figures, however, they included deaths due to more than one drug (as did Barraclough $^{3}$ and Girdwood ${ }^{4}$ ). If the King and Moffat ratios are recalculated for a representative series of antidepressants and other drugs, including only deaths due to one drug alone, the difference diminishes for all drugs except nortriptyline and chlorpromazine (table III).

Amitriptyline has been implicated in roughly half of all deaths attributed to tricyclic antidepressants in this study and in others both in the United Kingdom and in the United States. ${ }^{51314}$ It has been suggested that amitriptyline and its congeners, principally

TABLE III-Comparisons of fatal toxicity indices (deaths per million prescriptions) in this study with those of King and Moffat $(1983)^{\star}$

\begin{tabular}{|c|c|c|c|}
\hline \multirow[b]{2}{*}{ Drug } & \multicolumn{2}{|c|}{ King and Moffat (1983) covering 1976-8 } & \multirow{2}{*}{$\begin{array}{c}\text { Own data } \\
\text { covering 1975-84 } \\
\text { based on drug only } \\
\text { deaths }\end{array}$} \\
\hline & As published & $\begin{array}{l}\text { Adjusted to be based } \\
\text { on drug only deaths }\end{array}$ & \\
\hline Propranolol & $5 \cdot 6$ & $4 \cdot 3$ & $4 \cdot 5$ \\
\hline Oxprenolol & $7 \cdot 0$ & $4 \cdot 3$ & $3 \cdot 2$ \\
\hline Chlorpromazine & $99 \cdot 8$ & $51 \cdot 8$ & $22 \cdot 8$ \\
\hline Dextropropoxyphene† & $24 \cdot 4$ & $20 \cdot 5$ & $30 \cdot 6$ \\
\hline Amitriptyline & $80 \cdot 3$ & $43 \cdot 6$ & $46 \cdot 5$ \\
\hline Doxepin & $78 \cdot 9$ & $40 \cdot 4$ & $31 \cdot 3$ \\
\hline Dothiepin & $77 \cdot 5$ & $51 \cdot 7$ & $50 \cdot 0$ \\
\hline Trimipramine & $70 \cdot 5$ & $32 \cdot 6$ & $27 \cdot 6$ \\
\hline Imipramine & $64 \cdot 2$ & $39 \cdot 7$ & $28 \cdot 4$ \\
\hline Clomipramine & $42 \cdot 6$ & $14 \cdot 2$ & $11 \cdot 1$ \\
\hline Nortriptyline & 34.9 & $14 \cdot 4$ & $39 \cdot 2$ \\
\hline
\end{tabular}

^For King and Moffat's study mortality figures were for England and Wales, whereas prescription data were for England alone. Our data for both mortalities and prescriptions were for England, Wales, and Scotland.

tIncluding combined preparations containing aspirin or paracetamol. nortriptyline and doxepin, may be more toxic in overdose than imipramine and its congeners (desipramine, clomipramine, trimipramine, dothiepin, and dibenzepin). ${ }^{15}$ The reasons for the different toxicities of the drugs used to treat depression deserve consideration. It is now generally accepted that the fatal toxicity of the tricyclic antidepressants is principally due to their membrane stabilising activity. ${ }^{16}$ It has been suggested that the toxicity of amitriptyline and imipramine is reduced by detoxification to the more water soluble (and therefore less lipid soluble) metabolites, nortriptyline and desipramine. ${ }^{517}$ In this study, however, the fatal toxicity indices for amitriptyline and nortriptyline were very similar to that for imipramine. Desipramine has also been shown to cause seizures in overdose more often than other tricyclic antidepressants. ${ }^{18}$ This may be analogous to the greater membrane stabilising potency of the metabolite norpropoxyphene compared with its parent drug, dextropropoxyphene. ${ }^{19} 20$ Studies of erythrocytes in vitro have shown that desipramine is a more potent membrane stabilising agent than imipramine. ${ }^{21}$ The reason for the lower toxicity of clomipramine is less clear as it has been shown in similar studies to have greater membrane stabilising potency than either imipramine or desipramine..$^{22}$ Other factors, such as prescribing habits, may also play a part in the observed differences.

The monoamine oxidase inhibitors have fairly high fatal toxicity indices, yet the mechanism by which they cause a fatal outcome in overdose is not well understood and does not seem to be due to membrane stabilising activity. The clinical pattern of toxicity, with gradually increasing muscle spasms leading to hyperthermia, ${ }^{11}$ may cause respiratory failure, rhabdomyolysis, and disseminated intravascular coagulation. Their rapid oral absorption and short elimination half life (tranylcypromine two hours, phenelzine one hour) suggest that the drug is largely eliminated from the body by the time the clinical features of toxicity have built up to a life threatening degree. Though most of those who take overdoses of tricyclic antidepressants die outside hospital, the gradually progressive nature of toxicity caused by monoamine oxidase inhibitors suggests that more people might seek medical help as symptoms develop. The toxicity of these drugs might, however, be underestimated as postmortem toxicology would not show the cause. It is thus difficult to develop the comparison between the lethal toxicity of monoamine oxidase inhibitors and tricyclic antidepressants as the mechanisms and clinical patterns of toxicity are so different.

The group of newer antidepressants had a low mean fatal toxicity index, which suggests that progress has been made in producing less toxic drugs. The finding that maprotiline, a newer drug with a bridged tricyclic structure, has a fatal toxicity index similar to that of older antidepressants and greater than that of other new compounds is in accordance with the results of other studies, which have shown it to be as toxic as or possibly more toxic than earlier tricyclic antidepressants, particularly with respect to its ability to induce seizure ${ }^{15} 1823$ and cause death at similar plasma concentrations. ${ }^{17}$ The other agents in this group have much lower toxicity indices, which are not statistically different from each other $\left(\chi^{2}=7 \cdot 7\right.$, with $\left.5 \mathrm{df}\right)$. It remains to be seen whether any will emerge as more toxic. Mianserin is devoid of anticholinergic effects and produces few symptoms in overdose. ${ }^{24}$ Lofepramine has been described as having low toxicity ${ }^{11}$; it comes just short of significance in this study. Trazodone is a chemically and pharmacologically unique drug that has been reported to have little central nervous toxicity and no cardiac or anticholinergic activity in overdose $^{1118232526}$; it possesses lower membrane stabilising activity than amitriptyline or imipramine, ${ }^{27}$ which may explain its fairly low fatal toxicity index in this study.

When prescribing antidepressant drugs the doctor usually considers the toxic risks from self poisoning as well as from adverse effects. Regulatory authorities, however, tend to grant licences not on the toxicity of drugs in overdose but on their safety in therapeutic use. This is understandable as predicting acute toxicity in overdose is not feasible before a drug goes on sale. Once a drug has been on sale for some time data such as those presented here, viewed in the context of the overall morbidity and mortality related to the drug, could be considered by regulatory authorities when a drug comes up for renewal of licence. ${ }^{28}$ 
This study has shown that amitriptyline and several related tricyclic antidepressants have higher fatal toxicity indices than the monoamine oxidase inhibitors, which are in turn more toxic than several newer antidepressants. All of the drugs introduced since 1973 have a favourable toxicity profile except maprotiline. If the newer drugs have as good a record of clinical effectiveness, combined with their apparent lower potential to cause fatal poisoning when taken in overdose, serious consideration should be given to preferentially prescribing the newer drugs, especially to patients who are considered at particular risk of suicide by ingestion of an overdose of their medication.

We thank Squibb Europe Inc, Roussel Laboratories Ltd, Smith Kline and French Ltd, Pfizer Ltd, and the Lawson Tait (Humane Research) Trust, for financial support. We thank the statistics and research division of the Department of Health and Social Security for giving us access to prescription data and the Office of Population Censuses and Surveys for providing us with unpublished mortality data. We also thank Ms J Turner for statistical advice and $\mathrm{H} W$ iseman for help in preparing the manuscript.

\section{References}

1 Brewer C, Farmer R. Self poisoning in 1984: a prediction that didn't come true. $\mathrm{Br}$ Med $\mathcal{F}$ 1985;290:391

2 Osselton MD, Blackmore RC, King LA, Moffat AC. Poisoning associated deaths between 1973 and 1980. Hum Toxicol 1984;3:201-21.

3 Barraclough BM. Are there safer hypnotics than barbiturates? Lancet 1974;i:57-8.

4 Girdwood RH. Death after taking medicaments. BrMed f 1974;i:501-4.

5 King LA, Moffat AC. A possible index of fatal drug toxicity in humans. Med Sci Law 1983;23: 193-8.

6 Stead AH, Moffat AC, King LA. Quantitative structure-activity relationships in forensic toxicology. In: Dearden JC, ed. Quantitative approaches to drug design. Oxford: Elsevier, 1983:277-8.
7 British Medical Association and the Pharmaceutical Society of Great Britain. British national formulary. London: British Medical Association, 1975-84.

8 Association of the British Pharmaceutical Industry. Data sheet compendium. London: Association of the British Pharmaceutical Industry, 1975-84.

9 Office of Population Censuses and Surveys. Mortality statistics-accidents and violence (England and Wales). London: HMSO, 1975-84. (Series DH4.)

10 Registrar General. Annual report: mortality statistics. Scotland: General Register Office, 1975-84.

11 Blackwell B. Antidepressant drugs. In: Dukes MNG, ed. Meyler's side effects of drugs. 10th ed. Oxford: Elsevier, 1984:24-61.

12 Vale JA, Buckley BM, Meredith TJ. Deaths from paracetamol and dextropropoxyphene Vale JA, Buckley BM, Meredith TJ. Deaths from paracetamol and dextropropoxyphe

13 Callaham M, Kassel D. Epidemiology of fatal tricyclic antidepressant ingestion: implications for management. Ann Emerg Med 1985;14:1-9.

14 Crome $P$, Newman $B$. Why patients die from tricyclic antidepressant poisoning. Vet Hum Toxicol 1979;21(suppl):56-8.

15 Crome P, Newman B. The problem of tricyclic antidepressant poisoning. Postgrad Med $\mathcal{J}$ 1979;55:528-32.

16 Pentel PR, Benowitz NL. Tricyclic antidepressant poisoning: management of arrhythmias. Medical Toxicology 1986;1:101-21.

17 King LA. Ferguson's principle and the prediction of fatal drug levels in blood. Hum Toxicol 1985;4:273-8.

18 Wedin GP, Oderda GM, Klein-Schwartz W, Gorman RL. Relative toxicity of cyclic antidepressants. Ann Emerg Med 1986;15:797-804.

19 Nickander RC, Emmerson J, Hynes MD, Steinberg MI, Sullivan HR. Pharmacologic and toxicologic effects in animals of dextropropoxyphene and its major metabolite norpropoxy phene: a review. Hum Toxicol 1984;3(suppl):13-36S.

20 Zaman S, Lamb JM, Esberger DA, Pearson RM. Inhibition of sperm motility by opiate drugs. $B$ f Clin Pharmacol 1984;18:302P.

21 Yasuhara H, Tonooka M, Kamei K, Sakamoto K. Membrane effects of various drugs on isolated rat hepatocytes and erythrocytes. Toxicol Appl Pharmacol 1985;79:453-60.

22 Yasuhara H, Matsuo H, Sakamoto K, Ueda I. Mechanism of membrane stabilising and lytic effects of tricyclic antidepressants. Ipn f P harmacol 1980;30:397-401.

23 Kulig K. Management of poisoning associated with "newer" antidepressant agents. Ann Emerg Med 1986;15:1039-44.

24 Wakeling A. Efficacy and side effects of mianserin, a tetracyclic antidepressant. Postgrad Med $\mathcal{J}$ 1983;59:229-31.

25 Ali CJ, Henry JA. Trazodone overdosage. Experience over five years. Neuropsychobiology 1986;15(suppl 1):44-5.

26 Rawls WN. Trazodone. Drug Intell Clin Pharm 1982;16:7-13.

27 Cassidy SL, Henry JA. Rapid in vitro techniques for the assessment of the membrane stabilizing activity of drugs. Food Chem Toxicol 1986;24:807-9.

28 Leonard BE. Toxicity of antidepressants. Lancet 1986;i:1105.

(Accepted 9 September 1987)

공

\section{SHORT REPORTS}

\section{Secretor state of patients with insulin dependent or non-insulin-dependent diabetes mellitus}

The inability to secrete the water soluble glycoprotein form of the $A B O$ blood group antigens is associated with increased susceptibility to several infections, particularly among children in the vulnerable period between losing maternal antibodies and developing their own active immunity. ${ }^{1}$ This is a characteristic that does not alter with age or environmental influences.

The secretor $(\mathrm{Se})$ gene is located on chromosome 19; it is not linked to sex or to the histocompatibility locus antigen (HLA) markers. We have also found a considerable increase in the proportion of non-secretors (se) among patients who have ankylosing spondylitis, a rheumatic condition that has a close association (about $95 \%$ of cases) with the HLA B27 marker and for which an infectious aetiology has been postulated. ${ }^{2}$ As viral infections have been suggested to contribute to the development of type I diabetes, ${ }^{3}$ a recent

\section{Patients, methods, and results}

During six weeks 205 diabetic patients were examined (102 insulin dependent (56 men and 46 women); 103 non-insulin-dependent ( 60 men and 43 women)). The patients were recruited from those attending routine clinics; the first five to 12 patients at each session were asked to participate. None of the patients was admitted to hospital. Patients who had type I disease were classified by insulin dependence, their clinical history, and family history of the disease. The patients who had type II disease were not dependent on insulin.

The $\mathrm{ABO}$ and Lewis blood groups were determined by agglutination and the secretor state by the haemagglutination inhibition method from saliva. The Lewis group was used to confirm the results obtained from the saliva sample. The results were compared with those found for local blood donors by $\chi^{2}$ test.

There was no significant difference in the distribution of the ABO blood groups between the insulin dependent and non-insulin-dependent diabetic patients $\left(\chi^{2}=0.5911, \mathrm{df}=3, \mathrm{p}>0.50\right)$, and the results were similar to those found for local blood donors (type I: $\chi^{2}=3 \cdot 702, \mathrm{df}=3, \mathrm{p}>0 \cdot 10$; type II: $\chi^{2}=1 \cdot 266, \mathrm{df}=3$, $\mathrm{p}>0.50$ ). Among the patients who had type II disease there was no significant difference in the proportion of non-secretors (25\%) compared with the controls. Among the patients who had type I disease the proportion of non-secretors was significantly increased $(40 \%)\left(\chi^{2}=6 \cdot 223, p<0 \cdot 02\right)$ (table).

Blood group and secretor state of patients with type I and type II diabetes mellitus. All figures are numbers (percentages) of patients

\begin{tabular}{|c|c|c|c|c|c|c|c|}
\hline & \multicolumn{4}{|c|}{ ABO blood group } & \multicolumn{2}{|c|}{ Secretor state } & \multirow[b]{2}{*}{ Significance } \\
\hline & A & B & 0 & $\mathbf{A B}$ & Secretor $(S e)$ & Non-secretor $(s e)$ & \\
\hline $\begin{array}{c}\text { Diabetic patients: } \\
\text { Type I }(n=102) \\
\text { Type II }(n=103) \\
\text { Controls }(n=334)\end{array}$ & $\begin{array}{r}35(34) \\
37(36) \\
104(31)\end{array}$ & $\begin{array}{l}11(11) \\
11(11) \\
42(13)\end{array}$ & $\begin{array}{r}56(55) \\
53(51) \\
173(52)\end{array}$ & $\begin{array}{r}2(2) \\
15(4)\end{array}$ & $\begin{array}{r}61(60) \\
77(75) \\
245(73)\end{array}$ & $\begin{array}{l}41(40) \\
26(25) \\
89(27)\end{array}$ & $\begin{array}{c}\mathrm{p}<0.02 \\
\mathrm{NS}\end{array}$ \\
\hline
\end{tabular}

editorial on the genetics of this disorder ${ }^{4}$ prompted us to compare the secretor state of patients who have type I disease with those who have type II disease. If there were a parallel with ankylosing spondylitis we predicted that there would be a higher proportion of non-secretors among the patients who had type I diabetes.

\section{Comment}

Among the patients studied there were probably clinical and genetic heterogeneities within the insulin dependent and non-insulin-dependent groups; secretor state, however, is an additional, easily determined genetic 